\title{
Adaptation and acclimatisation in humans and animals at high altitude
}

\author{
David Williams
}

Rapid ascent into high altitude or permanent residence there leads to a wide range of disturbances of function or alterations in histological appearances in most organs of the body. The influences which lead to these changes are those inherent in the environment of high altitude, especially hypobaric hypoxia resulting from the diminished barometric pressure. One of the major aspects of research carried out at the Department of Pathology at Liverpool over the last 25 years has been the study of the effects of hypobaric hypoxia on the histological structure of the pulmonary circulation of lowlanders and lowland animals exposed to high altitude, of native highlanders, and of indigenous mountain mammals.

In some mammals, including man, the hypobaric hypoxia of high altitude induces a mild degree of pulmonary arterial hypertension with associated alterations in the structure of the peripheral portions of the pulmonary arterial tree. In other species it does not. This paper gives an account of the histological structure of the pulmonary circulation in the two groups - namely, the reactors and the non-reactors and seeks to establish the difference in the biological status of the two groups. The biological variety at high altitude can best be illustrated by taking a mental stroll around the streets and surrounding countryside of any small settlement in the Andes. One such is the mining town of Cerro de Pasco $(4330 \mathrm{~m})$ in central Peru where much of the work at Liverpool began.

Most of the people in the streets of Cerro de Pasco are native Quechua Indians born and bred in the Andes. These people have very characteristic physical features and deeply polycythaemic and suffused conjunctivae and lips. Some will have a capacious chest which looks prominent and out of proportion to their short stocky physique. These highlanders lead normal busy lives; they shop, go to school, visit the cinema, and play football at altitudes exceeding the summit of the Matterhorn.

Living on the pastures surrounding Cerro de Pasco are examples of indigenous mountain animals such as the llama (Lama glama), the alpaca ( $L$ pacos), the vicuña ( $L$ vicugna), and the guanaco ( $L$ guanacoe). These species have been living on the Andean altiplano for many thousands of years, preceding the appearance of the Quechuas. One cannot help but be impressed by the vigour and activity of the animals in an atmosphere characterised by severe hypobaric hypoxia. Other indigenous

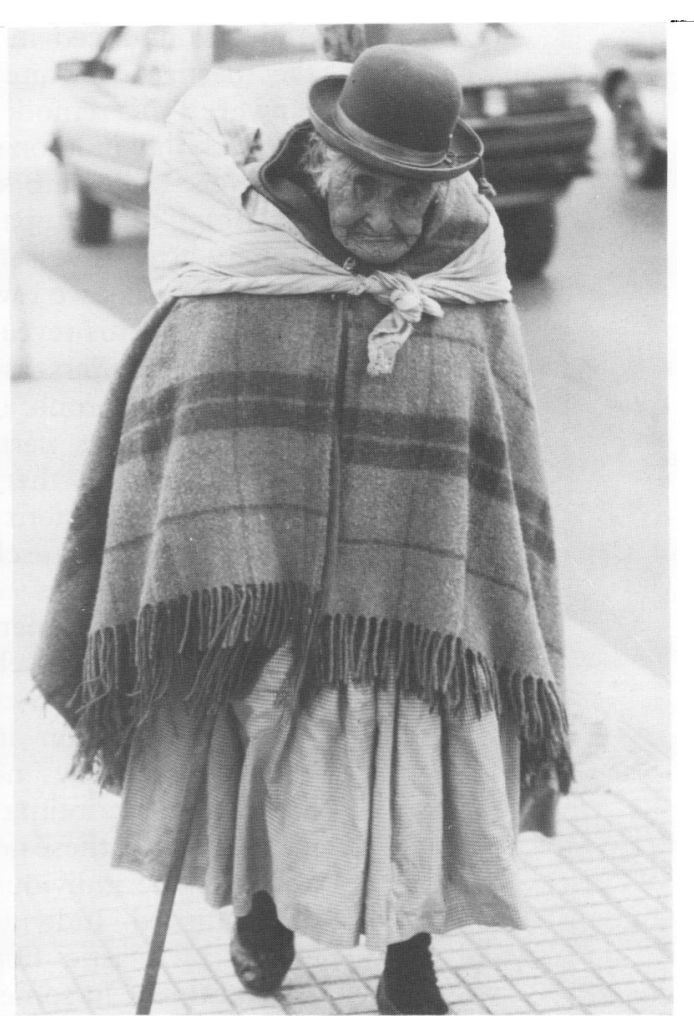

Figure 1 An Aymara Indian from La Paz. Most female Aymara Indians retain a traditional form of dress with layers of multicoloured skirts and a brown felt hat.

cacha (Lagidium peruanum) live at even greater altitudes exceeding $6000 \mathrm{~m}$. A further biological group comprises those domesticated animals such as cattle brought to high altitude by man. In other parts of the world these domesticated species may interbreed with indigenous relatives such as the yak (Bos grunniens).

\section{Humans}

The human pulmonary arterial tree at low altitude is a thin walled, low resistance system. "Muscular pulmonary arteries" less than $300 \mu \mathrm{m}$ in external diameter have a medial thickness of less than $5 \%$ of the external diameter of the vessel. ${ }^{1}$ They give rise to pulmonary arterioles less than $70 \mu \mathrm{m}$ in diameter which have a rim of circular muscle only at their site of origin, but elsewhere have a wall consisting of a single elastic lamina. In the highlander the parent arteries show little or no increase in medial thickness, no fibrinoid necrosis, and the development of primary pulmonary hypertension is unknown to the Andes. 
The impact of alveolar hypoxia on the human pulmonary arterial tree is at its most peripheral portions, composed of the pulmonary arterioles and the precapillaries. These vessels show a complex remodelling with the new development of vascular smooth muscle so that the pulmonary arterioles become muscularised with a distinct media of circular muscle sandwiched between inner and outer elastic laminae. In citizens of $\mathrm{La} \mathrm{Paz}(3800 \mathrm{~m}$ ) (fig 1) we have found vessels as small as $25 \mu \mathrm{m}$, hardly more than the diameter of an alveolar macrophage, with a distinct muscular coat looking like a small artery. ${ }^{2}$ This muscularisation is more pronounced in native Aymaras than in the mestizo or white inhabitants of the city. However, this remodelling of the terminal portions of the pulmonary arterial tree may be complex. Following a report in the literature describing the histopathology of the small pulmonary arterial vessels in 10 cases of hypoxic cor pulmonale ${ }^{3}$ we reviewed our material from the Andes. This revealed similar lesions in the native highlanders as had been described in the cases of chronic obstructive lung disease. Accordingly we carried out a second investigation on further material from $\mathrm{La} \mathrm{Paz}{ }^{4}$ The additional lesions consisted of a deposition of longitudinal muscle in the intima of the pulmonary arteries and arterioles, and the development of inner muscular tubes in the lumens of these vessels (fig 2). ${ }^{4}$

The smallest muscular pulmonary arteries (less than $200 \mu \mathrm{m}$ in diameter) commonly showed eccentric nodules of longitudinal muscle in the intima which bulged into the lumen. Within these nodules the cytoplasm and nuclei of the individual muscle cells could be distinguished. Individual myocytes were separated by elastic fibrils which had formed around them. In some pulmonary arteries col-

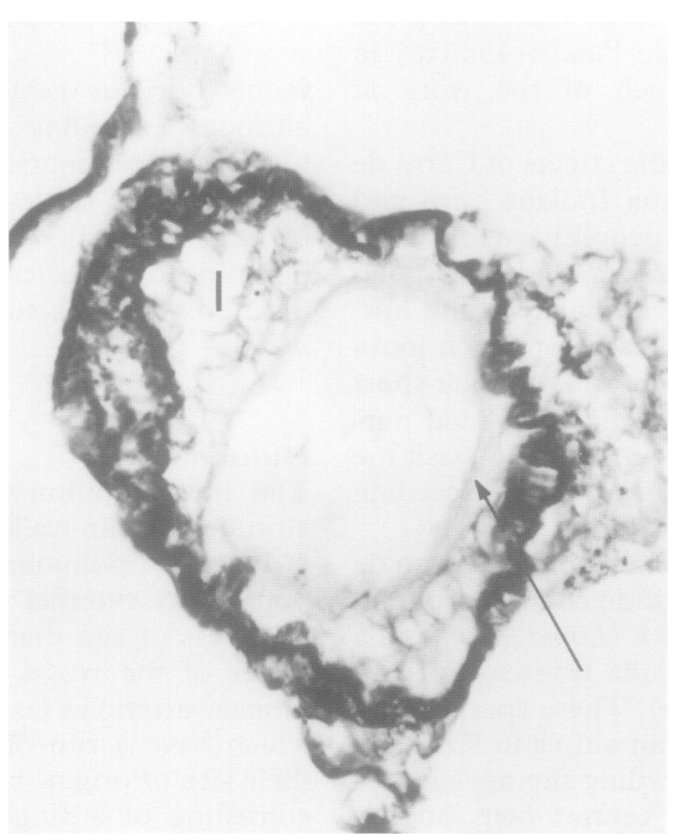

Figure 2 A pulmonary arteriole from an Aymara Indian showing the original thick elastic lamina, a layer of longitudinal muscle ()), and an inner muscular tube (arrow). Stain: elastic van Gieson, magnification $\times 745$. lagen had developed between the muscle cells and in isolation these appearances could have been misinterpreted as severe age change intimal fibrosis. Although the lesions in the pulmonary arteries were eccentric and nodular, the appearances were not those of organising or organised thrombus and no "colander lesions" of recanalisation were found. Sometimes intimal nodules of longitudinal muscle were found in muscularised pulmonary arterioles and in expanded precapillaries arising from them.

The beginnings of a thin muscular coat, composed of circularly orientated smooth muscle, could be seen lining the nodules of intimal longitudinal muscle in some pulmonary arteries bounded on their inner and outer surfaces by exceedingly thin elastic laminae (fig 2). The inner muscular tubes extended through the pulmonary arterioles with their thicker single elastic lamina. Internal to the lamina was a coat of longitudinal muscle which, in turn, was lined by the inner muscular tube. In smaller pulmonary arterioles the layer of longitudinal muscle disappeared so that the muscular tube came to lie next to the original thicker elastic lamina of the arteriole.

It has been known for many years that Quechua Indians living in the areas of Cerro de Pasco $(4330 \mathrm{~m})$ and Morococha $(4540 \mathrm{~m}$ ) in Peru have pulmonary hypertension. This is moderate (mean pulmonary pressure $45 \mathrm{~mm} \mathrm{Hg}$ ) in young children ${ }^{5}$ and slight (mean pulmonary arterial pressure $28 \mathrm{~mm} \mathrm{Hg}$ ) in adults. ${ }^{6}$ In addition, Arias-Stella and Saldaña ${ }^{7}$ showed that the underlying biological basis for the pulmonary hypertension was the associated muscularisation of the terminal portions of the pulmonary arterial tree. The findings of AriasStella and Saldaña ${ }^{7}$ were original and of great importance but described only part of a more complex overall picture.

However complex this remodelling process may be at high altitude, it is noteworthy that it is controlled, with the vascular smooth muscle cells remaining adherent to one another. This is in striking contrast to a second form of remodelling of the human pulmonary circulation at high altitude - subacute infantile mountain sickness. ${ }^{8}$ This disease occurs in infants of Han origin who are taken by their Chinese parents to live at high altitude in Lhasa, Tibet and is regarded as an expression of failure to achieve initial acclimatisation to hypobaric hypoxia in the very young. There is a florid migration of vascular smooth muscle cells from the media of pulmonary arterioles and veins into the intima and lumen.

\section{High altitude camelids}

The most common representative of this group of animals seen in the Andes is the llama (Lama glama) (fig 3). This species is a representative of the high altitude camelids which have lived for countless millennia in the Andes. Our studies were designed to determine if the pulmonary circulation of indigenous mountain camelids differed according to whether they lived at sea level or high altitude. In these species the 


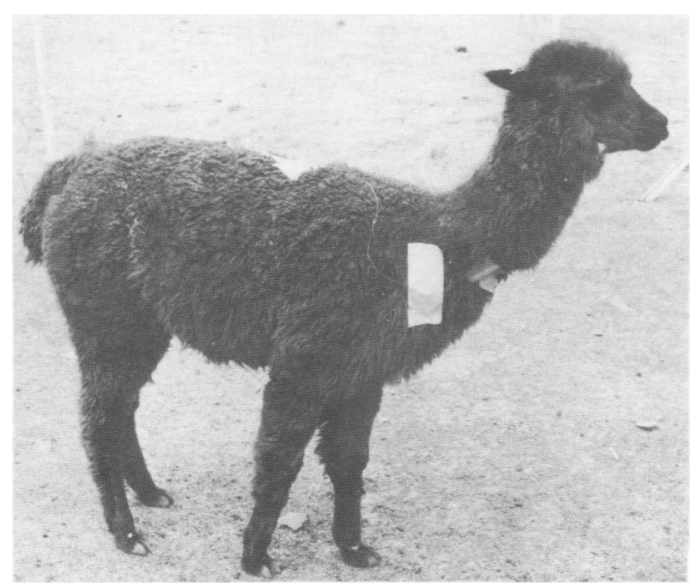

Figure 3 Llama from La Raya $(4200 \mathrm{~m})$. Following insertion of the catheter for cardiac catheterisation the animal was allowed to graze freely in the paddock.

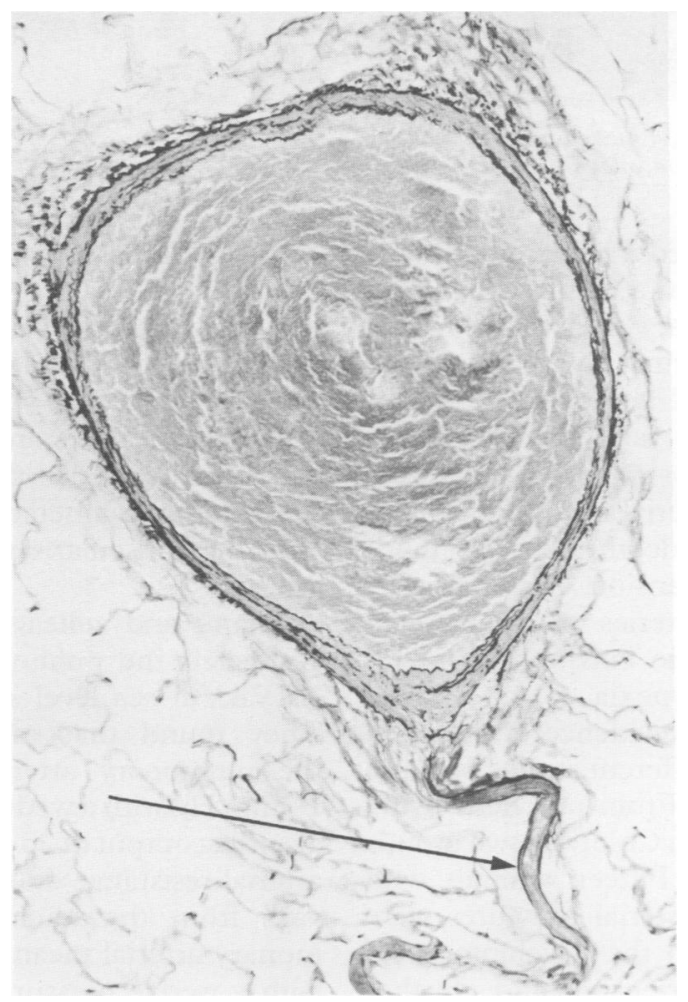

Figure $4 A$ thin walled "muscular pulmonary artery" from a llama at La Raya giving rise to a longitudinally sectioned pulmonary arteriole (arrow) devoid of a muscular media. Stain: elastic van Gieson, magnification $\times 150$.

muscular pulmonary arteries proved to be very thin walled and the pulmonary arterioles had a wall which consisted of a single elastic lamina (fig 4). ${ }^{9}$

It is not surprising that a pulmonary arterial tree with such a histological structure exhibits only a meagre response to environmental hypoxia. Direct measurement of pulmonary arterial pressure by cardiac catheterisation undertaken by Professor Peter Harris of the University of London showed that such animals manifest only a very slight rise in pulmonary arterial pressure above that shown by members of the same species living at sea level (table). ${ }^{9}$

Although it was argued that these observations support the concept of evolutionary forces at work to diminish the magnitude of
Mean pulmonary arterial pressure in camelids ${ }^{9}$

\begin{tabular}{|c|c|c|c|}
\hline \multirow[t]{2}{*}{$\begin{array}{l}\text { Situation and } \\
\text { altitude }\end{array}$} & \multirow[t]{2}{*}{$\begin{array}{l}\text { Species and } \\
\text { numbers }\end{array}$} & \multicolumn{2}{|c|}{$\begin{array}{l}\text { Pulmonary arterial } \\
\text { pressure }(\mathrm{mm} \mathrm{Hg})\end{array}$} \\
\hline & & Range & Mean \\
\hline London $(0 \mathrm{~m})$ & $\begin{array}{l}\text { Llamas (3) } \\
\text { Guanacos (3) }\end{array}$ & $3-14$ & 10 \\
\hline Lay Raya (4200 m) & $\begin{array}{l}\text { Llamas (12) } \\
\text { Alpaca (1) }\end{array}$ & $8-18$ & 14 \\
\hline
\end{tabular}

the hypoxic pulmonary constrictor reflex, it has to be conceded that the camel family is characterised by a thin walled pulmonary vasculature. The suggestion that the preservation of a thin walled pulmonary vasculature can be a feature of residence at high altitude and may be regarded as evidence of genetic adaptation to hypobaric hypoxia rather than acclimatisation requires further examination. It may be that the lack of muscularisation of the pulmonary arterial tree of the llama at high altitude is a reflection of the zoological affiliations of the species, rather than providing convincing evidence of genetic adaptation.

\section{High altitude rodents}

Most rodents, such as the mouse and the rat, respond to environmental hypoxia by muscularisation of the peripheral portion of the pulmonary arterial tree, which often leads to fatal congestive cardiac failure. However, certain rodents live exposed to natural high altitude for their entire lives. One such species living in the Andes is the mountain viscacha (Lagidium peruanum). It lives in the southern part of the Andes at altitudes up to $6500 \mathrm{~m}$ where it is exposed to a significant degree $\mathrm{rf}$ environmental hypoxia. Like the llama, the mountain viscacha maintains an exceedingly thin walled pulmonary arterial tree and has pulmonary arterioles devoid of a muscular media. ${ }^{10}$ This is in contrast to the effect that alveolar hypoxia has upon the pulmonary arterial tree of lowland rodents, and supports the concept that genetic adaptation to high altitude may be expressed in the pulmonary circulation as a loss or gross weakening of the hypoxic pulmonary vasoconstrictor response.

Support has also come from studies of the pulmonary circulation of an indigenous mountain rodent living at high altitude in a part of the world remote from the Andes. The animal concerned comes from Tibet where it is known as the Tibetan snow pig, despite being a variety of marmot (Marmota himalayana). Haemodynamic measurements revealed a low pulmonary arterial mean pressure and pulmonary arterial resistance, ${ }^{11}$ associated with a thin walled pulmonary arterial tree. The pulmonary arterioles were devoid of a muscular coat. ${ }^{11}$ These findings lend further weight to the concept that indigenous mountain species may be genetically adapted to high altitude and express this through a great weakening of the hypoxic pulmonary vasoconstrictor response.

\section{Cattle}

The hypothesis that a thin walled pulmonary vasculature may be a feature of genetic adapt- 


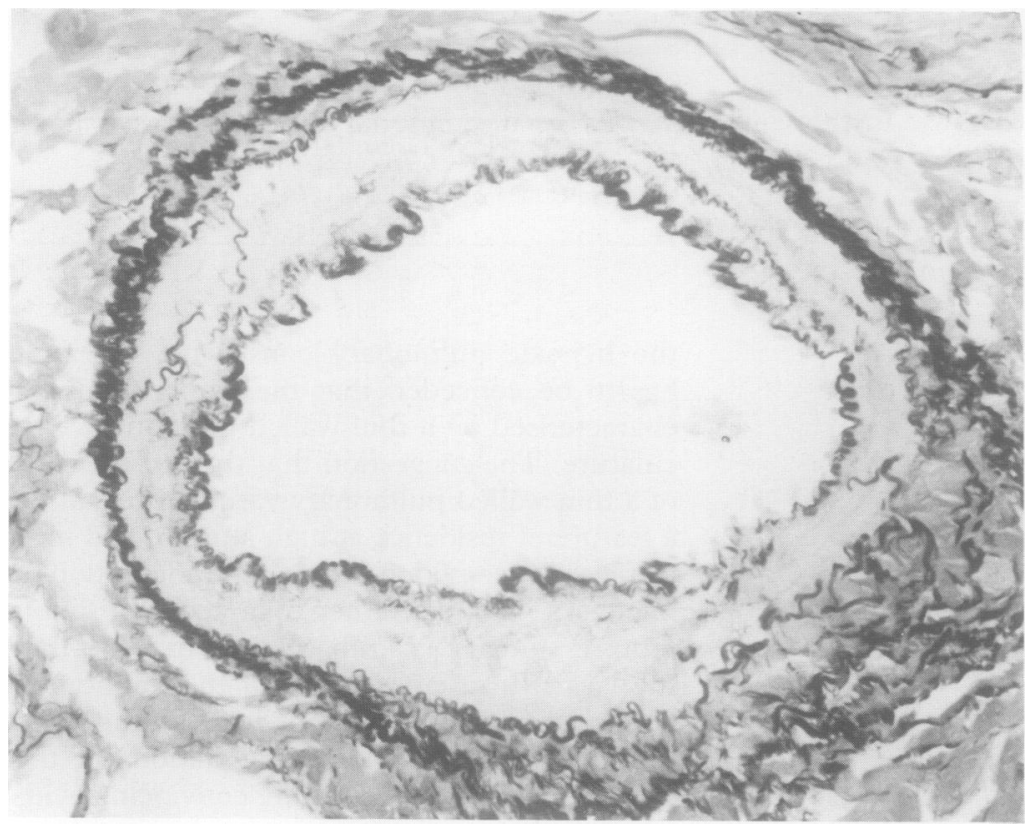

Figure 5 "Muscular pulmonary artery" from a cow at sea level showing a thick walled vessel with a medial thickness of $16 \%$. Stain: elastic van Gieson, magnification $\times 375$.

ation may be further tested if it could be shown that a representative from a family with a naturally muscular pulmonary arterial tree, living at high altitude, had thin walled vessels in contrast to its sea level zoological relatives. Such an animal is the yak (Bos grunniens). Domesticated cattle (Bos taurus) have a very muscular pulmonary arterial tree ${ }^{12}$ (fig 5 ) and, when taken to high altitude, they develop moderate pulmonary hypertension. The naturally muscular pulmonary arteries of cattle seem particularly susceptible to constriction in response to the alveolar hypoxia.

Furthermore, there is evidence of variation in the susceptibility of different strains of cattle to hypobaric hypoxia. ${ }^{13}$ From one herd living at an altitude of $3000 \mathrm{~m}$ in Colorado two groups of cattle were selected. Fifteen animals with the lowest pulmonary arterial pressures were designated "resistant" to the development of hypoxic pulmonary hypertension, and a further 10 animals with the highest pressures were considered to be "susceptible". ${ }^{13}$ Both groups were allowed to descend to an altitude of $1500 \mathrm{~m}$. They were kept separate from one another and their offspring were again studied at low and high altitudes. It was found that, on exposure to hypobaric hypoxia at $3000 \mathrm{~m}$, there was a much more pronounced rise in pulmonary arterial pressure in animals in the susceptible group than in those in the resistant group. A second generation of the two original groups was bred and the same striking differences emerged. These observations gave further support to the hypothesis that a genetic factor may be of importance in determining the reactivity of the pulmonary vasculature to the hypoxia of high altitude.

It therefore seemed of great biological interest to study the pulmonary circulation of the yak. Despite being a member of the cattle family which is characterised by a thick walled, muscular pulmonary vasculature (fig 5) res-

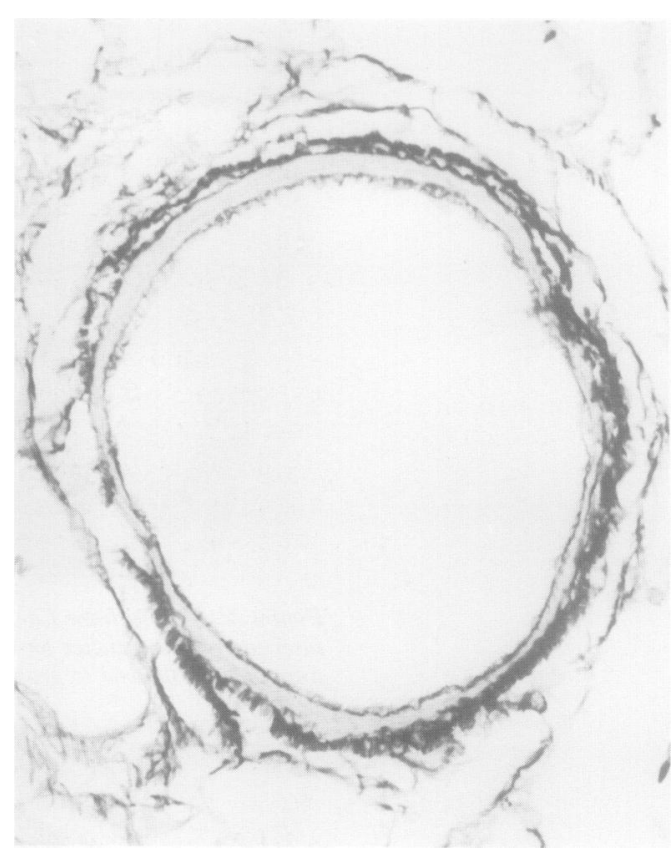

Figure 6 "Muscular pulmonary artery" from a yak from Sakti $(4500 \mathrm{~m})$ in the Himalayas showing a very thin media with a medial thickness of just over 3\%. Stain:

elastic van Gieson, magnification $\times 375$.

ponding to hypoxia by constriction, the yak is indigenous to altitudes exceeding $4000 \mathrm{~m}$ in the Himalayas. In spite of this its muscular pulmonary arteries are exceedingly thin (fig 6) with a mean medial thickness of only $4.5 \%$ of the external diameter of the vessel. ${ }^{1415}$ There was no muscularisation of the pulmonary arterioles.

Anand and colleagues ${ }^{16}$ had previously investigated the pulmonary haemodynamics of six yaks at sea level and five at high altitude. They found that in the yaks at sea level the pulmonary arterial mean pressure was $19 \mathrm{~mm} \mathrm{Hg}$ with a wedge pressure of $11 \mathrm{~mm} \mathrm{Hg}$, a cardiac output of $25.4 \mathrm{l} / \mathrm{min}$, and a pulmonary arterial resistance of $0.34 \mathrm{~mm} \mathrm{Hg} / 1 / \mathrm{min}$. In the yaks from the Ladakh Himalayas the pulmonary arterial mean pressure was $20 \mathrm{~mm} \mathrm{Hg}$ with a wedge pressure of $7 \mathrm{~mm} \mathrm{Hg}$, a cardiac output of $22.9 \mathrm{l} / \mathrm{min}$, and a pulmonary arterial resistance of $0.58 \mathrm{~mm} \mathrm{Hg} / \mathrm{l} / \mathrm{min}$. It was concluded that the pulmonary arterial pressure of Ladakhi yaks, at an altitude of about $4500 \mathrm{~m}$, was not significantly different from that found in the yaks bred at low altitude. Anand and his colleagues therefore concluded that the yak has adapted genetically to high altitude by largely eliminating the hypoxic pulmonary vasoconstrictor response. ${ }^{16}$

An intriguing aspect of such adaptation to high altitude by the yak is that it will readily crossbreed with cattle. It is therefore possible to observe the results of mating a member of the cattle family adapted to high altitude (yak) with one that is acclimatised and not very satisfactorily at that (cattle at high altitude). The commonest crossbreed arises from the mating of a cow with a male yak and is called a dzo. The female dzo is commonly mated with bulls to produce a further crossbreed called the stol. Anand et $a l^{16}$ found that the dzo had 
pulmonary haemodynamics similar to those found in the yak. On the other hand, half of the stols had pulmonary haemodynamics similar to those of the yak, while in the other half the findings resembled those in the cow. These results suggested to Anand and his colleagues that the genetic attenuation of the hypoxic vasoconstrictor response is transmitted as a simple Mendelian autosomal dominant trait. ${ }^{16}$ The argument outlined with respect to the diminished pulmonary vasoconstrictor response of the high altitude camelids and rodents may also therefore be applied to the yak. It would appear that the yak has a greatly diminished pressor response to hypobaric hypoxia, which has probably been lost through countless millennia of genetic adaptation to the mountain environment. Presumably natural selection has caused these animals to lose the thick walled, highly reactive pulmonary arteries characteristic of the genus in favour of those which are thin walled and relatively unreactive. This is powerful evidence in support of the concept that animals indigenous to high altitudes become genetically adapted to their hypoxic environment. This has enabled them to survive at high altitudes, in contrast to their zoological relatives (domestic cattle) which fare badly in mountains owing to the vasoconstrictive effects of hypoxia acting on their thick walled pulmonary arteries.

\section{Conclusions}

This programme of research has shown that the pulmonary arterial tree is frequently modified in humans and mammals living at high altitude, the nature of the modification depending on the biological status of the group of humans or animals being considered. Natural acclimatisation in humans is exemplified by the native Aymara or Quechua Indians of the Andes who have not lost their hypoxic pulmonary pressor response to alveolar hypoxia ${ }^{56}$ and show abnormal muscularisation of the pulmonary arterioles. $^{24}$ These vessels maintain an increased pulmonary vascular resistance and lead to slight pulmonary arterial hypertension. In a minority of native highlanders there is a more complex remodelling of the pulmonary arterial tree which is benign. ${ }^{4}$ It is hardly more than a marker of chronic alveolar hypoxia and has little or no effect on the wellbeing of the native highlander who carries out an active life of sustained manual work.

An alternative route to successful survival at high altitude may be achieved by genetic adaptation rather than natural acclimatisation. This is manifested by indigenous mountain mammals who appear to have lost their hypoxic pulmonary vasoconstrictor response totally or in large part. ${ }^{9-11}$ As a result their pulmonary arteries are thin walled and do not generate an increased pulmonary vascular resistance, so they do not show any noticeable rise in pulmonary arterial pressure. Such manifestations of genetic adaptation to hypobaric hypoxia are to be found in species native to the Andes, such as the llama, alpaca, ${ }^{9}$ and mountain viscacha, ${ }^{10}$ and to the Himalayas, such as the yak ${ }^{14}$ and the Tibetan snow pig. ${ }^{11}$

This long term programme of research first started at the Department of Pathology at the University of Birmingham and for the last 25 years has continued at Liverpool. During that time there have been several research expeditions to two of the great mountain ranges of the world, the Andes and the Himalayas. It is hoped that the studies of the pulmonary vasculature in humans and animals ascending to, or native to, these areas have shed some light on the response of the pulmonary circulation to high altitudes.

1 Heath D, Best PV. The tunica media of the arteries of the lung in pulmonary hypertension. 7 Pathol Bacteriol 1958 76:165-74.

2 Heath D, Smith P, Rios-Dalenz J, Williams D, Harris $P$ Small pulmonary arteries in some natives of $\mathrm{La} \mathrm{Paz}$ Bolivia. Thorax 1981;36:599-604.

3 Wilkinson M, Langhorne CA, Heath D, Barer GR, Howard P. A pathophysiological study of 10 cases of hypoxic cor pulmonale. $Q$ f Med 1988;66:65-85.

4 Heath D, Williams D, Rios-Dalenz J, Calderon M, Gosney J. Small pulmonary arterial vessels of Aymara Indians from the Bolivian Andes. Histopathology 1990;16:565-71.

5 Sime F, Banchero N, Peñaloza D, Gamboa R, Cruz J, Maricorena E. Pulmonary hypertension in children born Maricorena E. Pulmonary hypertension in children born

6 Peñaloza D, Sime F, Banchero N, Gamboa R, Cruz J, Marticorena E. Pulmonary hypertension in healthy men born and living at high altitudes. Am $\mathcal{F}$ Cardiol 1963;11 150-7.

7 Arias-Stella J, Saldaña M. The terminal portion of the pulmonary arterial tree in people native to high altitude. Circulation 1963;28:915-25.

8 Heath D, Harris P, Sui GJ, Liu YH, Gosney J, Harris E, et al. Pulmonary blood vessels and endocrine cells in subacute infantile mountain sickness. Respir Med 1989:83:77-81.

9 Harris P, Heath D, Smith P, Williams DR, Ramirez A, Krüger $\mathrm{K}$, et al. Pulmonary circulation of the llama at Krüger $\mathrm{K}$, et al. Pulmonary circulation of the

10 Heath D, Williams D, Harris P, Smith P, Krüger K, Ramirez A. The pulmonary vasculature of the mountain viscacha (Lagidium peruanum). The concept of adapted and acclimatized vascular smooth muscle. f Comp Pathol 1981 91:293-301.

11 Sun SF, Sui GJ, Liu YH, Cheng XS, Anand I, Harris P, et al. The pulmonary circulation of the Tibetan snow pig (Marmota himalayana). 7 Zool 1989;217:85-91.

12 Wagenvoort $\mathrm{CA}$, Wagenvoort $\mathrm{N}$. The pulmonary vasculature in normal cattle at sea level at different ages. Pathol Eur in normal cattle

13 Weir EK, Tucker A, Reeves JT, Will DH, Grover RF. The genetic factor influencing pulmonary hypertension in cattle genetic factor influencing pulmonary hypertension

14 Heath D, Williams D, Dickinson J. The pulmonary arteries Heath D, Williams D, Dickinson J. The pulm
of the yak. Cardiovasc Res 1984;18:133-9.

15 Anand I, Heath D, Williams D, Deen M, Ferrari R, Bergel $\mathrm{D}$, et al. The pulmonary circulation of some domestic animals at high altitude. Int $\mathcal{F}$ Biometerol 1988;32:56-64

16 Anand I, Harris E, Ferrari R, Pearce P, Harris P. Pulmonary haemodynamics of the yak, cattle and crossbreeds at high altitude. Thorax 1986;41:696-700. 